\title{
Edge finishing of large turbine casings using defined multi-edge and abrasive tools in automated cells
}

\author{
Adrian Rodríguez ${ }^{1} \cdot$ Mikel González $^{1} \cdot$ Octavio Pereira $^{1} \cdot$ L. Norberto López de Lacalle ${ }^{1} \cdot$ Mikel Esparta $^{2}$
}

Received: 19 April 2021 / Accepted: 16 September 2021 / Published online: 9 October 2021

(c) The Author(s) 2021, corrected publication 2022

\begin{abstract}
Automate finishing processes is a global challenge in several industrial sectors. Concretely, when dealing with aero-engine components, only simple finishing processes are automated nowadays. Most of the high-added value components manufactured are finished hand working, using deburring and polishing manual techniques. The driver of the proposed work is to achieve the necessary knowledge to introduce in a production line a complete finishing process for automated robotic deburring applications with low machinability materials (Inconel 718 in this case-study) on aero-engine casings with complex geometries: extruded casting bosses, internal features, etc. For this purpose, a three-step methodology is presented and analysed, providing a feasible workflow combining visual inspection for part positioning and edge location, with multi-edge solid tools and flexible abrasive tools to automate finishing operations, taking into account all process singularities. Results show that, using correct techniques, processes and parameters, an automated finishing process reducing operating time can be implemented in production lines.
\end{abstract}

Keywords Finishing $\cdot$ Deburring $\cdot$ Automation $\cdot$ Aeronautical $\cdot$ Inconel $\cdot$ Engine components $\cdot$ Robotics

\section{Introduction}

Manufactured components with functional surfaces usually require high surface finishes [1,2]. In many sectors, manufacturing processes such as milling, turning or hole making were commonly used. These processes generate undesirable surface quality caused by burrs, scratches, or insufficient finish. Traditionally, many finishing processes were handmade, mainly when dealing with complex geometries or high added value parts. Nevertheless, in the last years, there is a clear tendency of trying to automate as far as possible this kind of processes [3, 4].

Deburring processes deal with the elimination of nonpredictable material. Burrs generated during machining processes are difficult to characterize in a repeatable way

Mikel González

mikel.gonzaleze@ehu.eus

1 CFAA - Aeronautics Advanced Manufacturing Centre, University of the Basque Country (UPV/EHU), Biscay Science and Technology Park, Ed. 202, 48170 Zamudio, Spain

2 ITP Aero S.A, Parque Tecnológico n 300, 48170 Zamudio, Spain
[5]. This is, there are many different kinds of possible burrs generated and in some case their formation is aleatory. To define and develop techniques to eliminate burrs automatically, the first step is to be able to characterize the burr type and compare different part-references and batches in order to assure repeatability in the process of burr generation.

In 2003, a complete deburring and edge finishing handbook was published by Gillespie [6]. This work contains information regarding the commonly used deburring and polishing processes in manufacturing industry. Moreover, a complete classification of burr types was presented, characterizing burr in terms of their formation. In this line, the author differences six different types of burr formation: lateral creep due to compression, material bending, detachment from the chip (tear), redeposition of material, incomplete cutting, material creep due to breaks [7]. On the other hand, some other burr classifications were used in the last decades, such as the one proposed by Ramachandran et al. [8] which is based on four different families of burr mechanism formation (Poisson burr, roll-over, tear and separation without cutting). Other authors analyze the process of burr formation using material resistance criteria [9] or geometrical criteria, such as Schäfer [10] understanding the burr formation process using five geometrical parameters. The problem is 
that the measurements of the burr root thickness, the burr root radius and the burr thickness are difficult to perform non-destructively. Finally, the ISO 13715 [11] proposes a measure of burr height from the theoretical exit edge of the workpiece to the top of the burr.

Integration of robots in machining processes combines the advantages of the flexibility of manual operations with the repeatability of machine tools [12]. In the last years, deburring and polishing using automated robotic cells has reached great importance as super-finishing technology. Robot manufacturers present new specialized models for this kind of purposes, and new cell manufacturers provide solutions in this line [13], but not many aeronautical applications are shown industrialized, due to the high requirements of precision and repeatability. Furthermore, materials found in aero engine components present very low machinability, while most studies focus on applications with soft materials such as aluminium [14]. Materials such as Inconel 718 present major difficulties when it comes to machining, due to its excellent mechanical properties at high temperatures. Forces and temperatures in the cutting zone for this material are extremely high due to the high shear stress and low thermal conductivity [15]. On account of this, research that includes Inconel 718 among working materials for robotic deburring processes is very scarce. This kind of high added-value components, such as casings or radial structures, involve multiple manual processes within the last phase of the manufacturing process: the hand finishing operations. Due to a lack of technological development in the market that could fulfill the necessity in terms of quality requirements/ standards, in certain stages of the production processes, hand finishing remains necessary to guarantee the quality of a finished aero-engine part.

In this work, development was focused on intermediate module casings, Low Pressure Turbine (LPT) casings and radial structures, being the extruded bosses of these components the main case study. The amount of manual effort regarding these features, could represent the more than the half of the complete deburring process of a component. Regarding the architecture of a LPT casing (slim part), a radial structure (mechanized-welded part), or an intermediate module casing (casting-forging, mechanized-welded part), the same problem could be found: variability in feature edge location, geometrical variability of the burr generated in previous milling/turning steps, and final edge finishing control within defined limits.

Technologically speaking, some important developments were shown in scientific international papers to deal with the positioning problem. Automated deburring processes normally used pneumatic tools to obtain axial and radial tool compensation, as summarized in [16]. Some advances have been developed in this line. As an example, Ziliani et al. [17] proposes a mechatronic methodology for the active control of automated deburring of components with unknown geometry. In [18], Kim et al. proposes a new control process for deburring using pneumatic tools, modifying air flow and pressure in order to deal with the discontinuities between the part and the tool. In [19], Chen et al. propose a geometrical system compensating the toolpath in real time.

Path compensation is a widespread practice in casting deburring operations. Initially, these corrections were carried out by multi-point contact teaching methods along the parts [20]. Nowadays, many industrial application techniques use artificial automation methods to achieve highly accurate alignments [21-23]. Novel artificial vision systems are implemented in this kind of processes to measure the geometrical variations of the parts and automatically adapt the position, as presented by Princely [24]. Through a 3D scan of the part, stereolithographic (STL) model is generated, which is then used to adapt the nominal trajectory to the real part geometry [25]. However, artificial vision techniques have an associated positioning error which, although smaller than the effect of the dimensional variations of the part, must be taken into account. A possible solution combines vision positioning techniques with passive force-compensated tools (easier to implement and cheaper than active force systems) and establishes the process conditions in operations with low machinability materials, and no bibliographic background has been found in this line.

Thus, this work presents a detailed methodology for this purpose, including part positioning, features identification, edge cutting using conventional cutting tools and radii polishing using abrasive tools. The scope of this article is limited to defining the steps on which the process is based and analysing their feasibility so that they may be developed in the future in a fully automated way. Having performed several tests and iterations, early results show that a feasible methodology is possible combining different technologies. Concretely, to present real process data to support this methodology, three working lines are presented in this work: (i) geometrical inspection and analysis to identify the working features, (ii) deburring tests using force-compensated carbide tools in order to eliminate machining burrs and generate a chamfer, and (iii) polishing using abrasive tools to generate small radii to obtain a smooth edge geometry under requirements. Tests and results are supported and checked with surface measurements, including roughness, edge geometry and visual inspection. These advances define a methodology providing a clear workflow identifying the key aspects to achieve successfully a final component fitting the requirements.

\section{Industrial challenge and requirements}

The selected component to illustrate this work is the socalled outer case of a MTF (Mid Turbine Frame) of an aeronautical engine, but some other engine components present 
the same requirements and difficulties. In this work, a nonconfidential design is used as test part in order to provide a platform for the implementation of all the advances developed. In some part numbers, the outer case presents complex features called bosses. These bosses are commonly manufactured via casting process, obtaining a hybrid component formed by a casting ring assembled in an Inconel 718 forged casing, just as shown in Fig. 1. In a common process, after face-milling of boss shape features a high volume of manual deburring operations is necessary (more than $15 \mathrm{~h}$ in some cases). The aim of this work is to define a methodology in order to develop capability of doing automatic deburring tasks by on-machine adaptive deburring.

Boss shape features are the most critical and complex features in terms of deburring and finishing. These are extruded geometries obtaining via casting process. This manufacturing process provides a component with not so tight tolerances $( \pm 2 \mathrm{~mm}$ are commonly obtained values on these kind of components).

Comparing nominal geometry between real manufactured geometry, deviations on bosses can be of three different nature, these are: misalignments, overstocks or a combination of both. These deviations are the key to identify the correct edge location to perform the deburring and edge cutting process following the correct toolpath. Edge finishing shall be contained within a defined and controlled area, every edge shall be deburred (break sharp edge) within 0.1-0.4 mm, as shown in Fig. 2. For this purpose, a methodology based on three steps is presented in this work: (i) edge location and positioning, (ii) deburring and edge cutting, (iii) polishing sharp edges.

\section{Proposed methodology}

Obtain a feasible and automated finishing process for highadded value engine components is the driver of the proposed methodology. Some of these components are manufactured from casting rings, so processes developer must deal with notable variability regarding edge location and burr geometry and nature. A detailed step-by-step planning is presented in this paper, but in this section a general vision of the methodology is presented, as shown in Fig. 3. This methodology is based on three main steps:
Fig. 1 Outer case component description

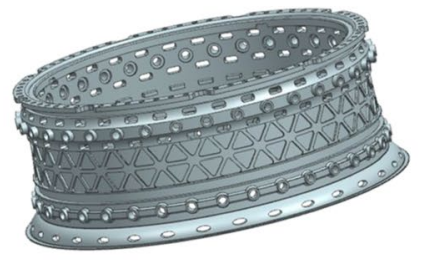

Component 1: Forge as raw material

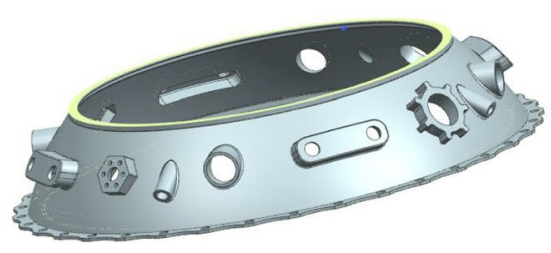

Component 2: Casting as raw material
Fig. 2 Edge location problems on boss shape features and edge finishing requirements

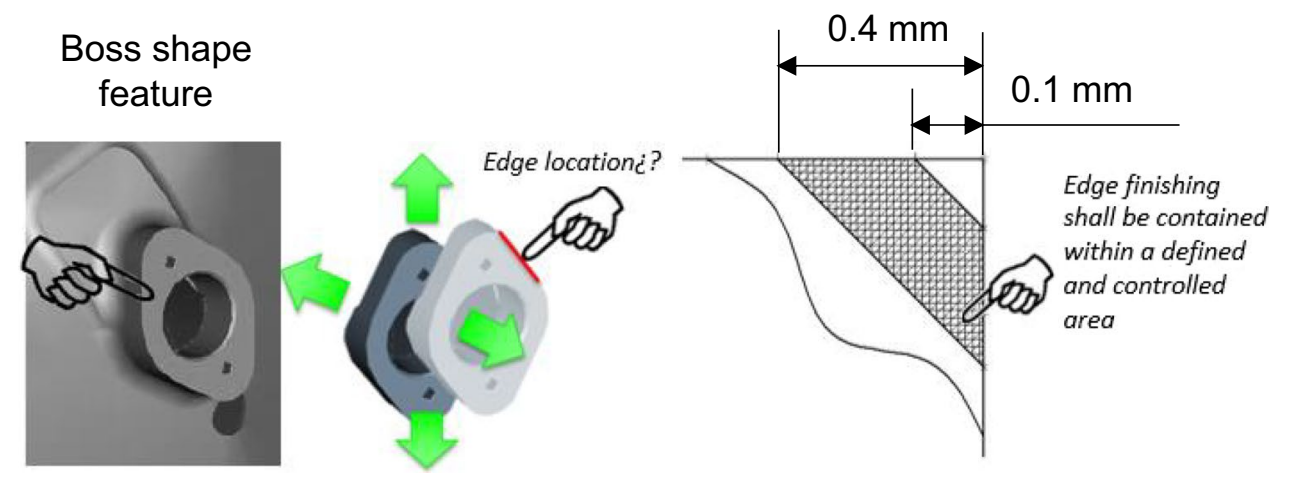


1. 3D scanning using non-contact geometrical measurement technologies. The idea is to obtain a cloud point of the real geometry to generate toolpaths that better adapt to part deviations. For edge detection, positioning is compared with the nominal geometry. Thus, real data of the edge location are obtained, improving positioning and ensuring uniform contact of cutting tool along workpiece.

2. Once the feature location is known, burrs removal process should be performed. Due to the width variability of burr types and sizes, different tools and cutting conditions should be studied. Multi-edge carbide tools allow complete removal of burrs by adjusting compensation force to the size of burrs.

3. Within the final finishing step not only the primary edges should be controlled. Depending on the requirements of the part, also the secondary edge geometries are defined and should be controlled. Thus, an abrasive tool should be used in order to finish and polish sharp edges, obtaining the required radii. For this purpose, the use of forcecompensated abrasive brushes is proposed.

The proposed methodology is based on a multi-step sequence combining $3 \mathrm{D}$ vision, adaptative toolpath generation and polishing technologies application. The challenge is focused on achieving a final component under requirements improving conventional methodologies which implies large amount of manual work and re-work due to the complexity of the geometries, their variability and the characteristics of this difficult-to-cut material.

\section{Equipment and material set-up}

The development of automated deburring technology is performed at the CFAA using the robotic super-finishing cell. This machine is manufactured by Getting Robotika for the model KUME DbR PE203. It is a designed cell capable of working in two different working modes (MOD1 and MOD2). Using it in MOD1, the tool is placed on the robot and the workpiece is fixed on the rotary table. In this mode, large components (Ø $2400 \mathrm{~mm}, 1500 \mathrm{~mm}$ height, $2500 \mathrm{~kg}$ weight) can be processed and tools are placed and moved using the robot and different spindles (electro spindle, pneumatic spindle, etc.). On the other hand, using the cell in MOD2, the workpiece is placed on the robot, which goes to the different fixed stations. This mode is commonly used with units or sets from casting approximate dimensions of $500 \times 500 \times 500 \mathrm{~mm}$ and maximum weights up to $90 \mathrm{~kg}$ ) and the operations to be performed include cutting and grinding in addition to other operations such as, deburring, polishing, measuring and control.

The robotic cell includes some elements: robot KUKA KRC4-KR240-R2500, 3D vision system, rotary table $\left(360^{\circ}\right.$ continuous rotation), electro spindle HSK63 $(22 \mathrm{~kW}$, $16,000 \mathrm{rpm})$, pneumatic force compensator, polishing line station $(5 \mathrm{~kW}, 50 \mathrm{~mm}$ width), cutting and polishing disk station ( $45 \mathrm{~kW}, 600 \mathrm{~mm}$ diameter), measuring and calibration station, a two-finger interchangeable head for MOD2, tool and head store and a laser pre-setter. This ad-hoc setup combining a rotary table and an articulated robotic arm was developed providing an adapted work environment for the component. This configuration provides a more flexible environment than cartesian alternatives, allowing access to all component features (Fig. 4).
Fig. 3 Finishing methodology proposed for casting boss shape features

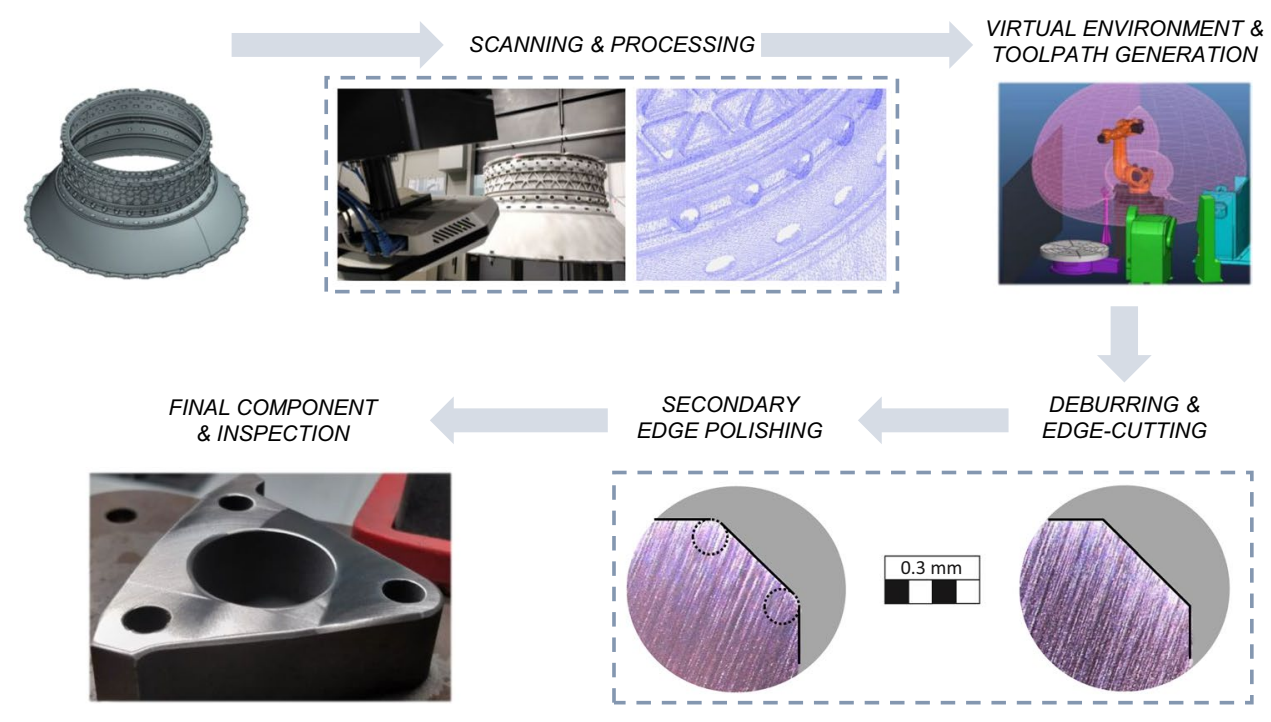




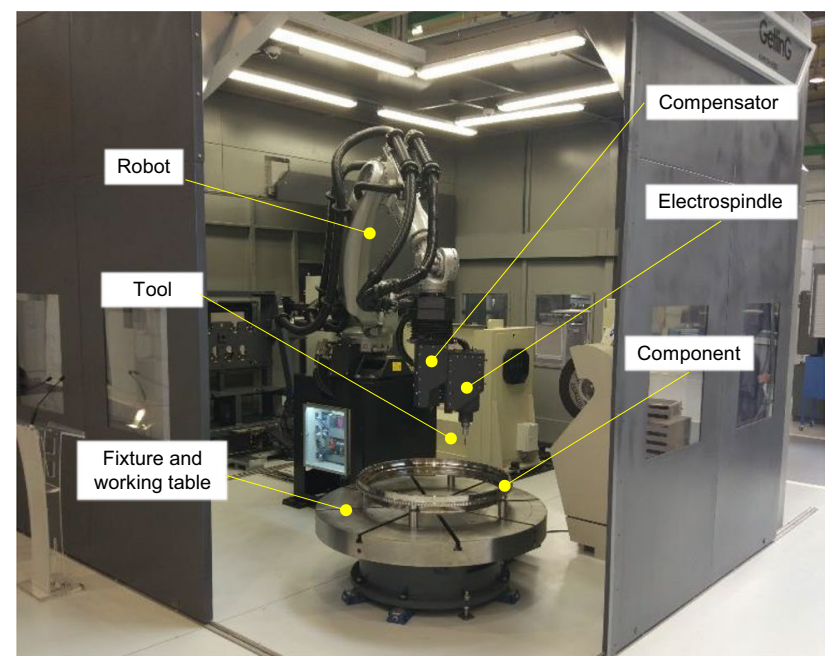

Fig. 4 Robotic cell working in MOD1 for polishing and deburring operations

Developments in this work are focused on a real aeronautical engine component, concretely the intermediate module casing with multiple bosses. These components are quite expensive and no so much scrap parts are available for testing. For this reason, a representative test part was designed and manufactured replicating the extruded bosses commonly observed in real components. The test part presents 3 extruded rows with a total of 9 extruded bosses. The dimensions are $250 \times 250 \times 30 \mathrm{~mm}$ and the material used was the same as the one used in the real component, this is, Inconel 718 aged (42-50 HRC). The test part was machined in order to obtain a representative burr according with the process of the real component (see Fig. 5). Thus, ceramic tools were used for this purpose, concretely the toolholder used was a $63 \mathrm{~mm}$ diameter face milling one (RNIW-063-06R) and the geometry of the inserts used were RNGN1207. To achieve similar burr generation, process parameters were the same that the ones used in the production line $(\mathrm{Vc}=600-800 \mathrm{~m} / \mathrm{min}$, $\mathrm{fz}=0.08-0.12 \mathrm{~mm}$, ap $=1-2 \mathrm{~mm})$.

\section{Part positioning and edge location}

Define and adjust a digital environment is the key aspect to achieve successfully a complete automate process. To represent the real component in a CAD/CAM software, it is necessary to define part positioning and, what is more important, edge location. Taking into account that boss shape features are manufactured with $\pm 2 \mathrm{~mm}$ tolerances, it is necessary to define and adjust these edges to be finished. For this purpose, non-contact scanning technologies are appropriate. Thus, this methodology starts with the implementation of a measurement operation, including: (i) calibration, (ii) scanning, (ii) edge identification, (iii) processing and (iv) toolpath adaptation (Fig. 6).

Structured blue light technology is used in this work. This technology provides the necessary scanning velocity for the required accuracy. Concretely an integrated Solutionix Rexcan CS2+ scanning head is used, and the scanning process is performed in the same finishing machine using the robotic arm to provide the required movements. This equipment can obtain 1-megapixel images with a ratio of 60 images per second. The processing software can control more than 100 million points in an easy way, and the lens used in this work provide a point spacing of $0.048 \mathrm{~mm}$, more than enough in order to locate the boss edges.

The first step is to calibrate the couple camera-robot. As the camera is moved by the robot, kinematic should be defined and calibrated. For this purpose, a calibrated standard patter should be scanned before process. Once scanned, calibration parameters are automatically calculated and the camera is ready to use. Then, the whole component should be scanned, focusing attention on the features to be machined/finished. Having obtained the cloud of points, edges must be identified and defined via CAD software and later on filtering should be applied to smooth the profile. To avoid the effect of burr dimensions in toolpath generation, edges are characterised to a lower plane, based on the already machined surface, and then translated into position. For profile smoothing, Bspline curve interpolation has proven to be effective in reducing surface faceting [26].
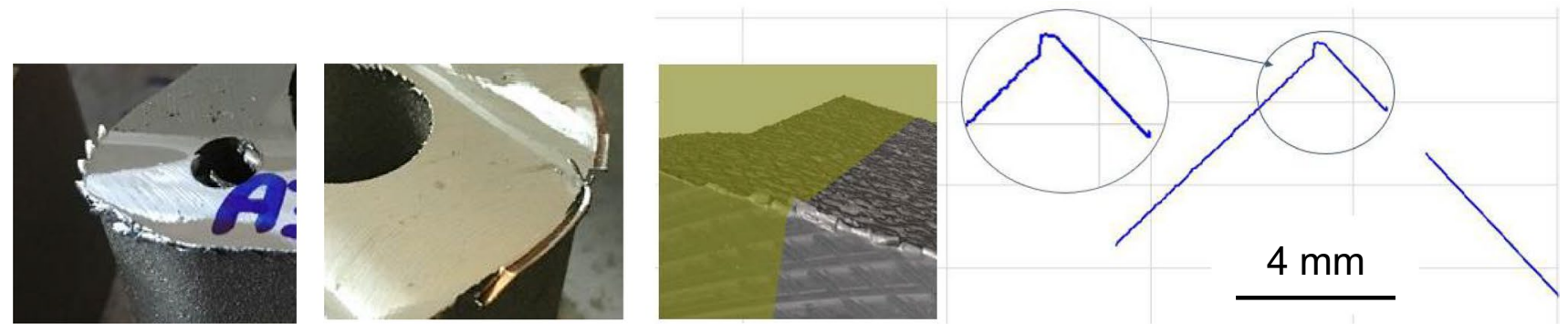

Fig. 5 Burrs generated on test part, similar to burrs obtained in real component 
Fig. 6 Edge location process and toolpath generation
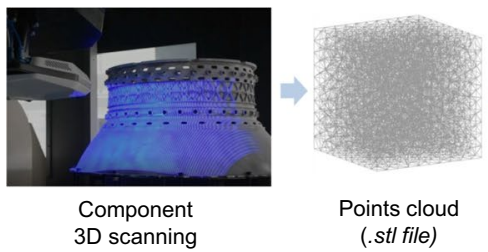

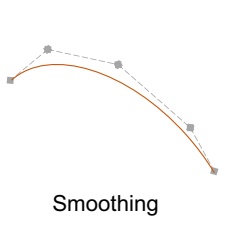

reconstruction

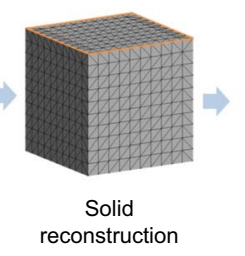

Smoothing

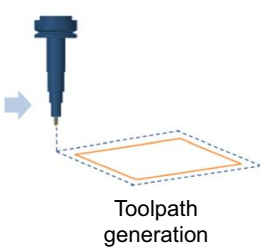

Smoothing reduces possible errors that may appear 3D scan technology. Interpolation errors are corrected using axial compensation tools, as explained in following sections.

When the profile is defined and located, toolpaths are generated or modified in accordance with process requirements. Virtual path generation is the key to achieve a zerodefect process performance. Thus, in near future deployment of digital twins should be studied in order to build a good real-virtual environment correlation for toolpath generation $[27,28]$.

\section{Deburring and edge cutting}

Deviations in position and dimensions of workpieces are the main problem when dealing with automate deburring. Part positioning can be corrected by using fixed tooling and scanner-based edge location, as shown in the previous section. However, obtained positioning by machine vision has an associated error that should also be taken into account. When robot performs the programmed toolpath, without taking into account the effect of these small deviations, the final result is an uneven cut along the contour of the piece, due to the effect of the variation of the contact position between the piece and the cutting tool (Fig. 7).

To minimize the effect of these imperfections, it is necessary to perform the deburring process using force compensation over the tool. This force control can be implemented using a special toolholder with axial force compensation. The one used in this work is a Sugino Barriquan BC10-10 model, which is based on a mechanical force control using interchangeable springs to compensate the axial movement of the cutting tool and maintain constant contact with the workpiece, as shown in Fig. 8. Thus, when tool is pushed too far into workpiece, the increase in contact force causes a retraction in the tool, keeping contact uniform throughout the process. Regarding cutting tool, it is commonly known that finishing difficult-to-cut materials such as Inconel 718, the use of solid carbide tools is the most common alternative for cutting edge. This is due to their superior material removal capabilities and wear resistance, as demonstrated in some other previous works. Moreover, to reproduce a $45^{\circ}$ chamfer, multi-edge conical-head tools are used as a most effective geometry reproducing the required edge and providing a constant edge orientation regardless of part variations.

Geometrical deviations on edges caused by burrs are inherent phenomena in the manufacturing process and cannot be accurately predicted or measured in an easy way. When programming deburring toolpaths based on the edge profile generated during scanner process, burrs are omitted by characterising edges at a distance below the reference plane of machined surface, as previously mentioned. However, variations in burr size cause changes in cutting force, disturbing contact of the tool with the workpiece. Therefore, if tools with axial force compensation are used, compensation force should be adjusted to the size of burrs in order to obtain a cut within tolerances. The arrangement and size of burrs along the edge are difficult to control, although it can be estimated based on operational conditions of machining processes, face milling in this case. The spring selection will be determined by the operating conditions of this previous machining.

This section presents a relation of experimental test performed to analyze the influence of force-control during this kind of irregular deburring processes. In an initial approach, a rigid tool holder is used to simplify the set-up and the investment. As mentioned before, some problems are
Fig. 7 Non-uniform cut along the edge profile due to irregularities of the geometry
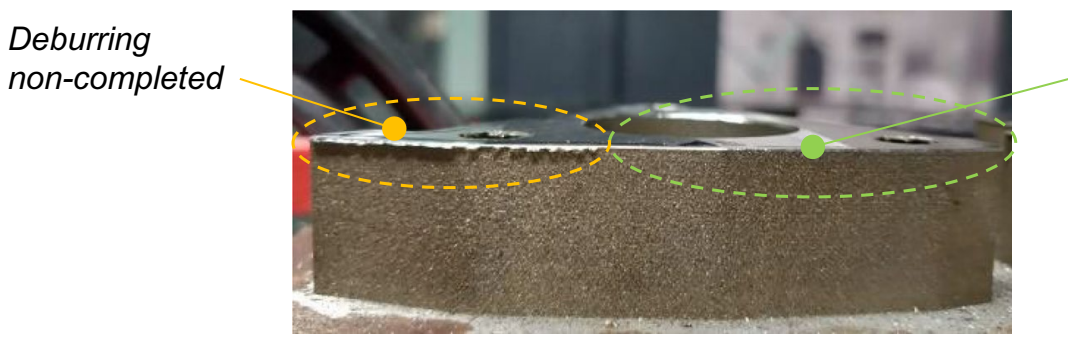

Deburring completed 
Fig. 8 Experimental set-up and cutting-edge requirements

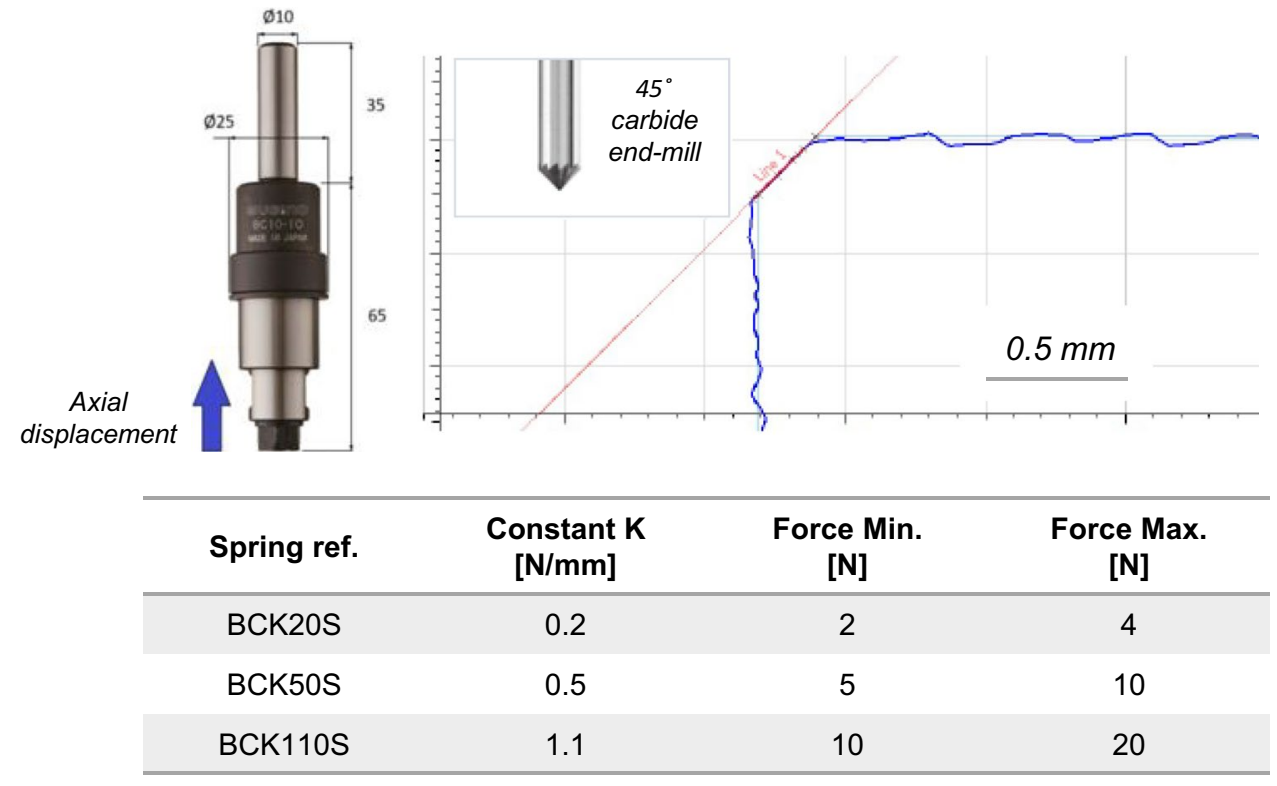

identified due to the rigidity of the system. This is, using this kind of toolholders a pure geometrical control is performed during the process, causing vibrations and non-uniform cut along the part edges. Indeed, it is necessary to perform a force-control based process in order to deal with the geometrical irregularities caused by burr and misalignments. Having demonstrated that a rigid solution is not adequate, some tests are performed using a special toolholder with 3 different types of force compensation, just as shown in Table 1.

Tests using the rigid toolholder show that the final results are not uniform at all. Moreover, some vibration appears during the process, obtaining a non-conformity in terms of roughness (required roughness $\leq 1.6 \mu \mathrm{m} \mathrm{Ra}$ ). Figure 9 shows that edge profile after the process is not uniform (not force compensation is used) because geometrical irregularities imply different cutting areas along the whole profile. Vibrations also are shown on the 3D topographical analysis and $2 \mathrm{D}$ profile shows that final edge profile is not under requirements.

Results using a non-rigid toolholder are also presented in this section. First, three different springs are tested in the inner holes of the workpieces to check the result of three different force levels. Force varies from 2 to $4 \mathrm{~N}$ (first level) to $10-20 \mathrm{~N}$ (third level). Figure 10 shows the aspect of three inner hole edges after being processed using different force values. For this couple tool-material, results show that the optimal force value to obtain under requirements results is below $5 \mathrm{~N}$ (first level), which is achieved using a spring with a constant value $K=0.2 \mathrm{~N} / \mathrm{mm}$. Visual inspection detects that a low value is the most feasible alternative for this purpose, allowing axial movement of the tool.

Once established an appropriate force level, a check test is performed processing all the contour of one of the bosses. Results show that all the profile is generated with a uniform chamfer, under tolerances. Figure 11 shows the test part, 3D topography and cutting section.

Using this tool and toolholder, deburring and edge cutting is performed in a correct way. However, two secondary sharp edges are generated after chamfering. This phenomenon should be avoided or minimized. Thus, a final step must be performed in order to achieve a smooth edge, necessary for the final assembly and delivery processes, when the component is finished.
Table 1 Experimental tests for edge cutting using solid multiedge tools

\begin{tabular}{llllll}
\hline No & Toolholder & Tool & Force control (N) & $\begin{array}{l}\text { Spindle } \\
\text { speed (rpm) }\end{array}$ & Feed (mm/min) \\
\hline 1 & Rigid & $45^{\circ}$ carbide end-mill & - & 16.500 & 120 \\
2 & & & - & 8.000 & 120 \\
3 & Barriquan BC10-10 & \multirow{4}{*}{$5^{\circ}$ carbide end-mill } & $2-4$ & 8.000 & 120 \\
4 & & & $5-10$ & 8.000 & 120 \\
5 & & & $10-20$ & 8.000 & 120 \\
\hline
\end{tabular}




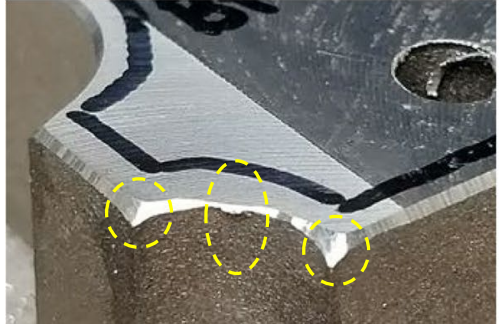

Non-uniform deburring and chamfering

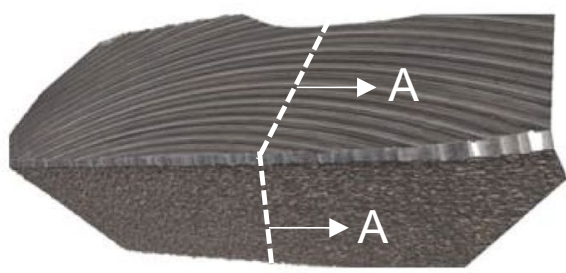

$3 \mathrm{D}$ reconstruction

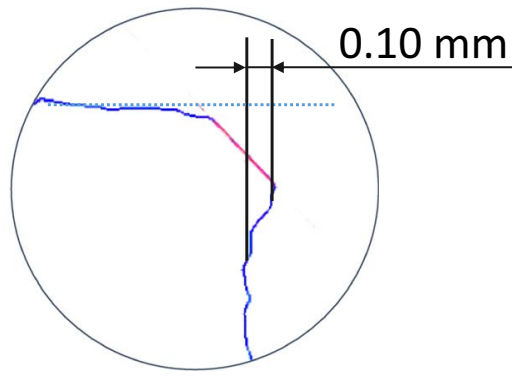

A-A section

Fig. 9 Visual inspection, 3D topographical measurement and 2D cut of the part edge using rigid toolholder
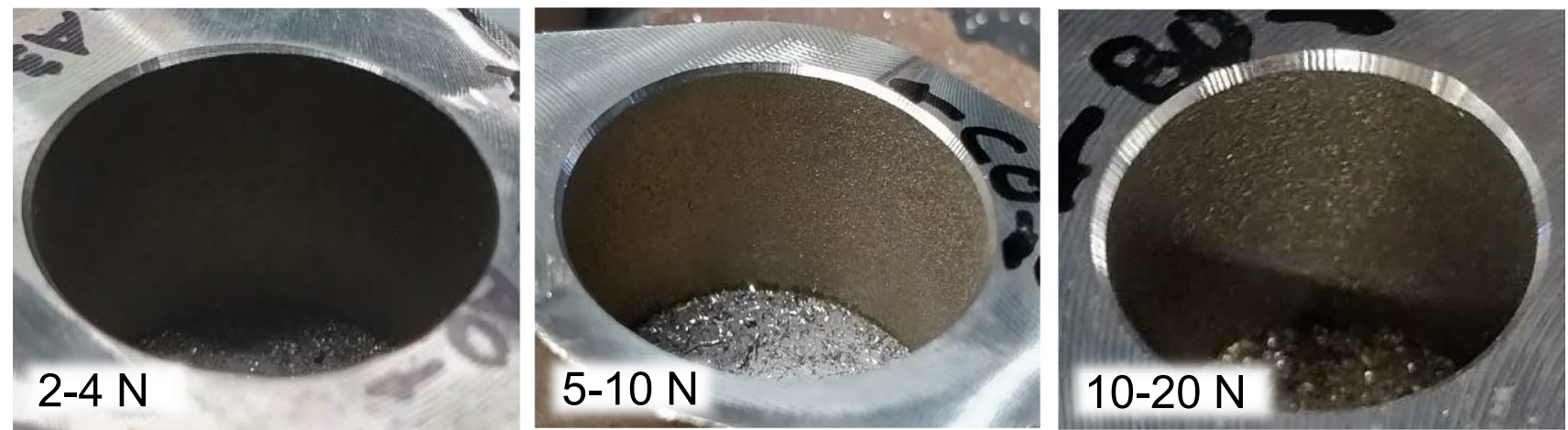

Fig. 10 Edge results using different force values during force-controlled process

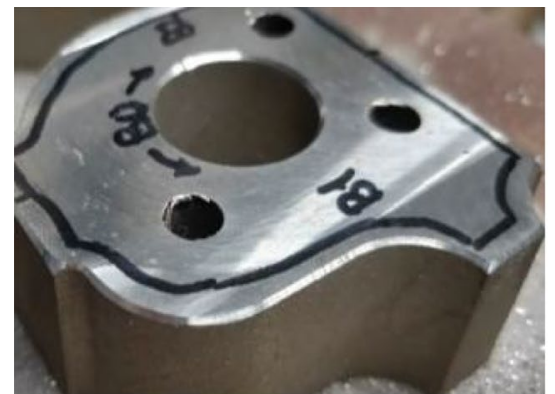

Test part

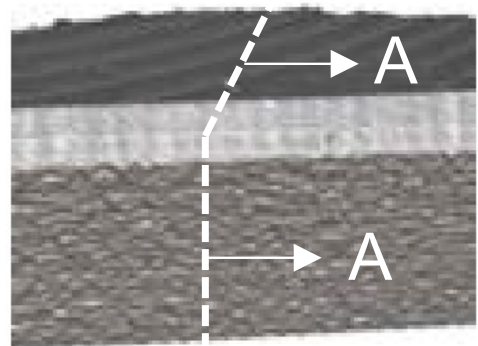

$3 \mathrm{D}$ reconstruction

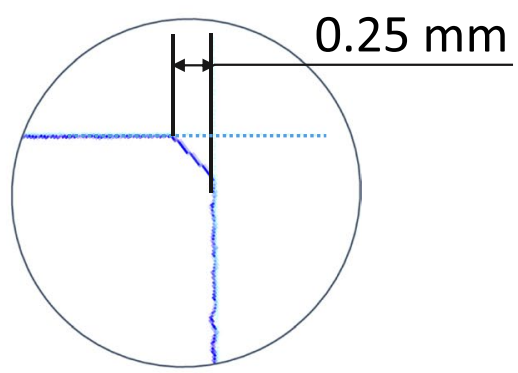

A-A section

Fig. 11 Visual inspection, 3D topographical measurement and cutting section of the part edge using force control

\section{Abrasive polishing of secondary edges}

Brushing turns out to be a very extended operation when providing the last finishing operation to the component, giving it a clean appearance with smoothed edges after erasing secondary edges and the previous deburring marks. Brushing tools with high abrasive capacity can be found nowadays in the literature [29], suitable for the removal of small burrs as well, thus reducing the finishing stages and with it, the total machining time and the operating costs of the process. In this work, A32-CB40M surface brushes from XEBEC were used, as show in Fig. 12.

This type of brushes work while maintaining their normal orientation to the workpiece. The use of axial compensation 


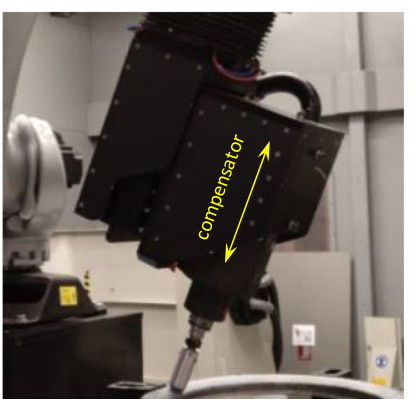

Spindle and force compensator

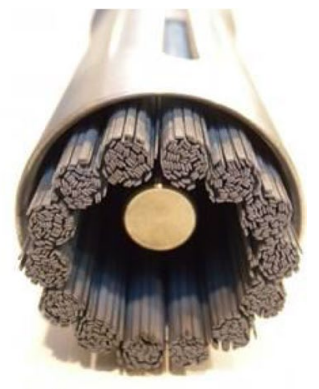

Flexible abrasive brushes
Fig. 12 Experimental set-up carried out using force controlled abrasive brushes

tools for this application provides the necessary pressure or force control, preventing breakage due to overloading of the fibers and allowing for varying material removal capacity. Brushing operating conditions for these initial trials were $2400 \mathrm{rpm}, 10 \mathrm{~mm} / \mathrm{s}$ feed rate along edge profile and $20 \mathrm{~N}$ axial compensation. Length projection of the brush was adjusted to $15 \mathrm{~mm}$, for a depth of cut of $1 \mathrm{~mm}$.

After polishing the test part, mechanical and optical cuts are performed to analyze the final edge result. Figure 13 shows the sharpness reduction on secondary edges, providing an under-tolerance result of the edge.

Taking into account the knowledge generated during the performance of this work, a general estimation of the capability to automate the process can be proposed. In a general view, it can be considered that using this methodology, approximately the $80 \%$ of a whole aero-case component can be finished in an automated way. It can be assumed that the other $20 \%$ must be completed in manual due to: (i) robot accessibility and capability to deal with complex geometries, and (ii) manual rework due to non-efficiently automated finishing. Assuming this approach, due to the higher velocity of the automated process compared with the manual one (more than twice in speed), a notable time saving can be introduced in the system. This reduction depends on the part number, reference and other indicators, but at least, an estimated value of $10-15 \%$ can be proposed as an initial point.

\section{Conclusions}

Technological methodology for automated finishing of aeroengine cases and similar components is presented in this work. Technologies and processes tested, offer to aeronautical market a chance for automating operations in which final quality is completely operator-dependent and not friendly in terms of health and safety. Results provided in this work show the following key conclusions:

Using a 3D scanner based on structured blue light, a rapid and accurate detection of component edges to be deburred can be performed. Edge detection is necessary for toolpath adaptation in order to generate new toolpath profiles to deal with real part geometry.

Minor profile deviations, i.e.: those derived from the scanning/smoothing process itself, are corrected by applying cutting tool force-compensation systems, keeping contact between tool and part as uniform as possible.

Application of radial compensation strategies can be useful when removing burrs with great root thickness. Combination of conical cutting tools and tool holders equipped with axial compensation shows the best results, transferring edge deviations in tool axial movements/oscillations.

Solid carbide end-mills provide high material removal rates deburring Inconel 718. Thus, to remove this kind of burrs, the use of carbide tools is recommended, varying forcecompensation according to the size of the burrs and the chamfer required.

For smaller burr sizes, or for secondary edge smoothing, flexible abrasive tools are the recommended solution. Abrasive brushing is proven to be a feasible solution for removing smaller burrs, thus enabling the reduction of deburring operations and reducing process operating time.

These results allow to identify the key aspects to develop this methodology in the future. In future work, efforts will be made to perform each stage in an automated way, establishing optimum process conditions for all types of parts likely to be presented.
Fig. 13 Visual inspection and 2D cut of the initial (before brushing) and final edge (after brushing)

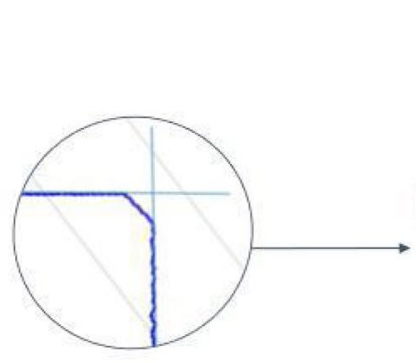

Edge before polishing

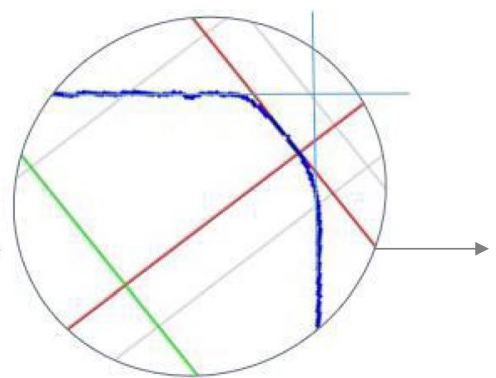

Edge after polishing

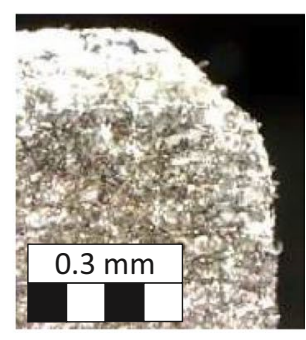

Edge section 
Acknowledgements Thanks are addressed to the HAZITEK program from the Department of Economic Development and Infrastructures of the Basque Government and from FEDER founds, related to the project with acronym FAKTORIA. Authors are also grateful to the Basque government group IT IT1337-19. Finally, thanks are owed to the Ministry of Mineco REF DPI2016-74845-R and PID2019-109340RB-I00.

Funding Open Access funding provided thanks to the CRUE-CSIC agreement with Springer Nature.

Data availability Data and material in this paper are original, available, and objective.

Code availability Not applicable.

\section{Declarations}

Conflict of interest Not applicable.

Ethics approval Not applicable.

Consent to participate All the authors consent to participate in this work.

Consent for publication All the authors in this work have consented to publish this manuscript.

Open Access This article is licensed under a Creative Commons Attribution 4.0 International License, which permits use, sharing, adaptation, distribution and reproduction in any medium or format, as long as you give appropriate credit to the original author(s) and the source, provide a link to the Creative Commons licence, and indicate if changes were made. The images or other third party material in this article are included in the article's Creative Commons licence, unless indicated otherwise in a credit line to the material. If material is not included in the article's Creative Commons licence and your intended use is not permitted by statutory regulation or exceeds the permitted use, you will need to obtain permission directly from the copyright holder. To view a copy of this licence, visit http://creativecommons.org/licenses/by/4.0/.

\section{References}

1. Rodríguez A, López De Lacalle LN, Fernández A, Braun S (2014) Elimination of surface spiral pattern on brake discs. J Zhejiang Univ Sci A 15:53-60. https://doi.org/10.1631/jzus.A1300236

2. Rodriguez A, de Lacalle LNL, Pereira O et al (2020) Isotropic finishing of austempered iron casting cylindrical parts by roller burnishing. Int J Adv Manuf Technol 110:753-761. https://doi. org/10.1007/s00170-020-05894-7

3. Da XuL, Xu EL, Li L (2018) Industry 4.0: state of the art and future trends. Int J Prod Res 56:2941-2962. https://doi.org/10. 1080/00207543.2018.1444806

4. Lu Y, Xu X, Wang L (2020) Smart manufacturing process and system automation: a critical review of the standards and envisioned scenarios. J Manuf Syst 56:312-325. https://doi.org/10. 1016/j.jmsy.2020.06.010

5. Pang X, Zeng Y, Zhang J, Deng W (2021) Analytical model and experimental verification of Poisson burr formation in ductile metal machining. J Mater Process Technol 290:116966. https:// doi.org/10.1016/j.jmatprotec.2020.116966
6. Gillespie L (1999) Deburring and edge finishing handbook. Society of Manufacturing Engineers

7. Gillespie L (2003) Hand deburring: increasing shop productivity. Society of Manufacturing Engineers

8. Ramachandran RN, Pande SS, Ramakrishnan N (1994) The role of deburring in manufacturing: a state-of-the-art survey. J Mater Process Technol 44:1-13. https://doi.org/10.1016/0924-0136(94) 90033-7

9. Aurich JC, Dornfeld D, Arrazola PJ et al (2009) Burrs-analysis, control and removal. CIRP Ann - Manuf Technol 58:519-542. https://doi.org/10.1016/j.cirp.2009.09.004

10. Shafer F (1975) Product design influences on deburring. Soc Manuf Eng 1:75-483

11. ISO (2017) ISO 13715 Technical product documentation: edges of undefined shape - indication and dimensioning

12. Ji W, Wang L (2019) Industrial robotic machining: a review. Int J Adv Manuf Technol 103:1239-1255. https://doi.org/10.1007/ s00170-019-03403-z

13. Driemeyer Wilbert A, Behrens B, Zymla C et al (2015) Robotic finishing process: an extrusion die case study. CIRP J Manuf Sci Technol 11:45-52. https://doi.org/10.1016/j.cirpj.2015.07.002

14. Niknam SA, Davoodi B, Davim JP, Songmene V (2018) Mechanical deburring and edge-finishing processes for aluminum parts-a review. Int J Adv Manuf Technol 95:1101-1125. https://doi.org/ 10.1007/s00170-017-1288-8

15. Arunachalam R, Mannan MA (2000) Machinability of nickelbased high temperature alloys. Mach Sci Technol 4:127-168. https://doi.org/10.1080/10940340008945703

16. Le ZhuW, Beaucamp A (2020) Compliant grinding and polishing: a review. Int J Mach Tools Manuf 158:103634. https://doi.org/10. 1016/j.ijmachtools.2020.103634

17. Ziliani G, Visioli A, Legnani G (2007) A mechatronic approach for robotic deburring. Mechatronics 17:431-441. https://doi.org/ 10.1016/j.mechatronics.2007.04.012

18. Kim C, Chung JH, Hong D (2008) Coordination control of an active pneumatic deburring tool. Robot Comput Integr Manuf 24:462-471. https://doi.org/10.1016/j.rcim.2007.04.003

19. Chen SC, Tung PC (2000) Trajectory planning for automated robotic deburring on an unknown contour. Int J Mach Tools Manuf 40:957-978. https://doi.org/10.1016/S0890-6955(99) 00099-1

20. Sugita S, Itaya T, Takeuchi Y (2004) Development of robot teaching support devices to automate deburring and finishing works in casting. Int J Adv Manuf Technol 23:183-189. https://doi.org/10. 1007/s00170-003-1602-5

21. Tsai JT, Lin CT, Chang CC, Chou JH (2015) Optimized positional compensation parameters for exposure machine for flexible printed circuit board. IEEE Trans Ind Inf 11:1366-1377. https:// doi.org/10.1109/TII.2015.2489578

22. Tsai JT, Yang PY, Chou JH (2018) Data-driven approach to using uniform experimental design to optimize system compensation parameters for an auto-alignment machine. IEEE Access 6:4036540378. https://doi.org/10.1109/ACCESS.2018.2856911

23. Tsai YT, Lee CH, Liu TY et al (2020) Utilization of a reinforcement learning algorithm for the accurate alignment of a robotic arm in a complete soft fabric shoe tongues automation process. J Manuf Syst 56:501-513. https://doi.org/10.1016/j.jmsy.2020.07.001

24. Leo Princely F, Selvaraj T (2014) Vision assisted robotic deburring of edge burrs in cast parts. Procedia Eng 97:1906-1914. https://doi.org/10.1016/j.proeng.2014.12.344

25. Azzam N, Chaves-Jacob J, Boukebbab S, Linares JM (2014) Adaptation of machining toolpath to distorted geometries: application to remove a constant thickness on rough casting prosthesis. Int J Adv Manuf Technol 72:1073-1083. https://doi.org/10.1007/ s00170-014-5738-2 
26. Lartigue C, Tournier C, Ritou M, Dumur D (2004) High-performance NC for HSM by means of polynomial trajectories. CIRP Ann - Manuf Technol 53:317-320. https://doi.org/10.1016/S00078506(07)60706-9

27. Tao F, Cheng J, Qi Q et al (2018) Digital twin-driven product design, manufacturing and service with big data. Int $\mathrm{J}$ Adv Manuf Technol 94:3563-3576. https://doi.org/10.1007/ s00170-017-0233-1

28. Roy RB, Mishra D, Pal SK et al (2020) Digital twin: current scenario and a case study on a manufacturing process. Int $\mathbf{J}$
Adv Manuf Technol 107:3691-3714. https://doi.org/10.1007/ s00170-020-05306-w

29. Kannan S, Kui L (2019) Experimental investigation of surface integrity during abrasive edge profiling of nickel-based alloy. $\mathrm{J}$ Manuf Process 39:40-51. https://doi.org/10.1016/j.jmapro.2019. 01.052

Publisher's Note Springer Nature remains neutral with regard to jurisdictional claims in published maps and institutional affiliations. 